\title{
Erratum
}

\section{Role of Trace Elements in Primary Arterial Hypertension}

\author{
Is Mineral Water Style or Prophylaxis?
}

\author{
SLAWOMIR TUBEK \\ Faculty of Physical Education and Physiotherapy, Institute \\ of Technology, Opole, Poland \\ (slawomir.tubek@hipokrates.org)
}

Received April 3, 2006; Accepted April 20, 2006

\begin{abstract}
A negative relationship between water hardness and cardiovascular mortality rate was demonstrated and became a source of interest regarding minerals and trace metals in the pathogenesis of atherosclerosis, cardiovascular diseases, and arterial hypertension. Higher incidences of sudden death, cerebrovascular diseases, arterial hypertension, and coronary heart disease have been reported in soft water areas. A major research effort has been devoted to the problem in an attempt to find a protective factor in hard water or a detrimental factor or element in soft water. The roles of calcium, magnesium, cobalt, lithium, vanadium, silicon, manganese, and copper have been considered potentially beneficial, whereas those of cadmium, lead, silver, zinc, and thallium have been considered potentially harmful. Cobalt and zinc have been attributed both roles. In the present article, the role of trace quantities of several elements in mineral water in the etiopathogenesis of primary arterial hypertension is reviewed.
\end{abstract}

